\title{
Alignment Of Two Grading Systems: A Case Study
}

Margaret Hohner, Thompson Rivers University, Canada

Panagiotis Tsigaris, Thompson Rivers University, Canada

\begin{abstract}
For the past number of years, a Canadian university has been offering its business degree program in universities located in Tianjin and Shanghai, China. This paper examines the alignment of the two grading systems and its implications on the grade distribution of graduates from the programs. An attempt is made to find an exchange rate of the two grading systems which reflects the fundamental value of the students' academic achievement.
\end{abstract}

Keywords: Transnational Programs, Academic Achievement, Comparative Analysis, Quality Assurance, Ethics in Education, Grading Policies, International Accreditation and Assessment

\section{INTRODUCTION}

$\mathcal{F}$

or the past number of years, a small Canadian university has been offering its business degree program in universities located in two Chinese cities through a joint agreement. ${ }^{1}$ The two partner institutions deliver the Canadian business degree curriculum in China using a combination of Chinese and Canadian faculty. In this twinning partnership model ${ }^{2}$, business students are required to satisfy both Chinese and Canadian degree requirements.

One of the many challenges in coordinating the programs across the different locations has to do with the different grading systems here and abroad. ${ }^{3}$ Grading systems within a nation and around the world vary widely and in Canada, grading systems vary by provinces, level of education, institution, and even by different divisions within the same institution. The grading system in place at the small Canadian university differs from the Chinese grading system and hence, there is a need to re-align the grading systems in order to create uniformity and standardization so that comparability can be conducted (Feagles, 1999) and program requirements met.

The difficulties experienced by the university in Canada are not much different than what has been documented by European Union (EU) universities. The credit transfer problem in the EU has been analysed by Guy Haug (1997) who states the following:

Grading systems differ in philosophy and practice from one country to another and the fair interpretation of foreign grades into national ones is a major issue, both for students returning after a study period abroad and for university staff required to assess the credentials of foreign applicants (Karran, 2004, p.413)

In the European Union, the problem of credit transfer from countries with different grading systems has been a point of controversy for years, resulting in 1999 of the implementation of the European Credit Transfer System agreement between 29 European nations. Even though this system has been widely promoted, there continues to be discrepancies with its use, as a "one size fits all" solution cannot fairly and ethically convert grades from systems that use vastly different assessment and achievement standards (Karran, 2004).

\footnotetext{
${ }^{1}$ Thompson Rivers University (TRU) in Canada and Tianjin (TUT) and Shanghai institutes (SIT) in China.

2 The various program models of globalization are described in Allan Bernardo's discussion paper (2002) such as Twinning, Branch Campuses, Franchise Agreements, Distance Education and Articulation Agreements.

${ }^{3}$ The first grading system was first implemented by the University of Cambridge in 1792 (Postman 1992).
} 
How to align the two grading systems to be reflective of the academic achievement of the students, irrespective of the location of delivery of the program, is what this research attempts to address. One way would be to follow the European system and align both systems into one grading system. In the analogy of the international financial market, instead of having two currencies, create one currency and make it available for all to use, thus the two grading systems are mapped into another grading system. However, this procedure is not feasible since each of the universities is governed by their own system which cannot be changed for the purpose of alignment. This requires a need to find an exchange rate of the two grading systems which reflects the fundamental value of the students' academic achievement. In the terminology of international finance, there is a need to find an appropriate exchange rate for one currency to be converted to the other.

Students report cumulative GPA in their curriculum vitae as it indicates to potential employers' the student's ability and is also used as an indicator for being accepted into graduate programs. Not only do the Chinese students who obtain this dual degree expect a higher prospect of getting a good job upon graduation, but this high number of graduate job placements raises the profile and rank of the Chinese Institution (Gribble \& Ziguras, 2003, p.211). Research done by Jones and Jackson (1990) also substantiates the claim that there is a positive association between undergraduate grade-point-average and post-baccalaureate earnings, making fairness in the calculation of grade-point-averages between the two institutions important for both the students and the partner institutions.

The current practice of the Canadian university is to deduct five marks from all final marks submitted by the universities located abroad. The five mark deduction has been justified on the basis that in China, a passing mark is 60 and at the Canadian university, a passing grade is usually 55; therefore, the 5-mark deduction is used as a measure to bring the Chinese marking scale in-line with the home university marking scale. This paper examines the impact of the deduction policy on the distribution of the grades of graduates from the offshore universities. A recommendation to change the policy will be provided that leads toward a more fair system. ${ }^{4}$

A review of the literature has revealed that there is very little quantitative research published on the academic achievement of students studying in transnational post-secondary business programs. To date, most of the literature published on transnational education has been concerned with cultural issues, student experiences, faculty experiences, monitoring of the imported education, international program equivalencies, quality standards and regulations. ${ }^{5}$

Although there is cultural research on how institutions can adapt their program delivery to better meet the diverse needs of their international student populations, the literature tends to focus on cultural adaptation, language proficiency, study skills and how institutions and teachers should adapt to the various needs of international learners. For instance, in a study by Glauco De Vita (2002), it is suggested that assessment methods used in delivering curriculum to international students may be culturally biased and that end-of-course examinations should be avoided in culturally diverse classrooms. Other studies assume that international students are academic underachievers and they require more support from institutions or need to put forth more effort themselves. ${ }^{6}$

Studies that analyse direct comparisons between domestic and international students within the same location have had inconclusive results. Some studies revealed that international students did better than domestic students and other studies revealed that domestic students performed better academically than the international students (Morrison, Merrick, Higgs, \& Le Métais, 2005). Research compiled by Jochems, Snippe, Smid \& Verweij (1996) in Denmark shows a significant correlation between successful student achievement and the level of language proficiency a student has in the language of study in a comparison of domestic and international students.

Other areas of research examine the politics of the globalization of higher education and institutional motivation for the creation of transnational programming. The past twenty years have seen a dramatic shift from traditional internationalization activities to the more economically driven globalization of higher education as

\footnotetext{
${ }^{4}$ This new policy has been adopted recently.

${ }^{5}$ See De Vita (2002); Abel (2002); Chapman \& Pyvis (2006); Gribble \& Ziguras (2003); McBurnie \& Ziguras (2001); Jones (2001); Gift, Leo-Rynie \& Moniquette (2006); Van Damme (2001)

${ }^{6}$ See Morrison, Merrick, Higgs, \& Le Metais (2005); Jochems, Snippe, Smid, \& Verweij (1996)
} 
institutions respond to the shift from a "technology society" to a "knowledge society". Unfortunately, when higher education becomes a commodity, sold to less developed countries, it has many negative side effects, one of which is the "favouring of the more well-developed education systems and institutions, thereby compounding existing inequalities" (Altbach \& Knight, 2006).

\section{GRADING SYSTEMS: HOME AND TRANSNATIONAL PROGRAMS}

The grading system, at the Canadian university, is governed by policy ED (24) 3-5 (TRU, 2007). The purpose of the policy is to create a grading system that has a uniform standard in order to be able to compare grading distributions across all of the institutional degree programs. All academic programs at the Canadian university are governed by Table 1. Instructors are required to provide to the registrar the final grades in letter grade form. In order to assist the instructors with the determination of the appropriate final letter grade, the numerical percentage range for each letter grade is provided in the policy as illustrated in Table 1 below. Each letter grade has a numerical grade point value assigned, which is then used to provide a based term and cumulative term grade point average.

Table 1: TRU Grading System

\begin{tabular}{|c|c|c|c|}
\hline $\begin{array}{l}\text { Letter } \\
\text { Grade }\end{array}$ & $\begin{array}{l}\text { Numerical } \\
\text { Grade }\end{array}$ & $\begin{array}{l}\text { Grade } \\
\text { Point }\end{array}$ & Letter Grade Description \\
\hline $\mathrm{A}+$ & $90-100$ & 4.33 & Excellent. First Class Standing. Superior Performance showing comprehensive, in- \\
\hline A & $85-89$ & 4.00 & depth understanding of subject matter. Demonstrates initiative and fluency of \\
\hline A- & $80-84$ & 3.67 & expression. \\
\hline $\mathrm{B}+$ & $77-79$ & 3.33 & Very Good. Second Class Standing. Clearly above average performance with \\
\hline $\mathrm{B}$ & $73-76$ & 3.00 & knowledge of principles and facts generally complete and with no serious \\
\hline B- & $70-72$ & 2.67 & deficiencies. \\
\hline $\mathrm{C}+$ & $65-69$ & 2.33 & Satisfactory. Basic understanding with knowledge of principles and facts at least \\
\hline $\mathrm{C}$ & $60-64$ & 2.00 & adequate to communicate intelligently in the discipline. \\
\hline $\mathrm{C}-$ & $55-59$ & 1.67 & Pass. Some understanding of principles and facts but with definite deficiencies. \\
\hline $\mathrm{D}$ & $50-54$ & 1.00 & $\begin{array}{l}\text { Minimal Pass. A passing grade indicating marginal performance. Student not likely } \\
\text { to succeed in subsequent courses in the subject. }\end{array}$ \\
\hline $\mathrm{F}$ & $0-49$ & 0.00 & $\begin{array}{l}\text { Unsatisfactory. Fail. Knowledge of principles and facts is fragmentary; or student } \\
\text { has failed to complete substantive course requirements. }\end{array}$ \\
\hline DNC & & 0.00 & $\begin{array}{l}\text { Did not complete the course - no official withdrawal or less than } 50 \% \text { of course } \\
\text { work completed. }\end{array}$ \\
\hline
\end{tabular}

In addition to the above policy, the business program (BBA hereafter) has its own requirements in terms of grades students achieve to graduate. In order to graduate with a BBA degree, students must maintain an overall CGPA of at least 2.0, and grades of C- (a GP of 1.67) or better in all core and major/minor or general BBA courses (TRU Academic Calendar 2007).

Table 2 shows the Chinese universities' grading system as compiled by Shelley Feagles (1999) in “A Guide to Educational Systems Around the World"7:

Table 2: Chinese Grading System

\begin{tabular}{|c|c|l|}
\hline Letter Grade & Numerical Grade & \multicolumn{1}{c|}{ Letter Grade Description } \\
\hline A & $90-100 \%$ & You (优) is considered excellent performance \\
\hline B & $80-89 \%$ & Liang (良) is considered good overall performance \\
\hline C & $70-79 \%$ & Zhong(中) means average or fair performance \\
\hline D & $60-69 \%$ & Ji'ge(及格) means pass or satisfactory \\
\hline F & $0-59 \%$ & Cha(差) means unsatisfactory or fail \\
\hline
\end{tabular}

\footnotetext{
${ }^{7}$ According to the TRU Associate Registrar, this grading scale is recommended, but final credit and grade evaluation is ultimately determined by a student's home university.
} 
As shown in Appendix A, the two grading systems are not aligned. The percentage grades that fall in the various categories differ. For example, the home university policy has a grade in the $80 \mathrm{~s}$ assessed as excellent performance, while in China, this grade range falls in the good overall performance. Trying to align the performance of students by using the common terms "excellent", "good", "satisfactory", "minimum achievement", as well as "failure", in the two policies will lead to a two-letter grade reduction in the grade point average of the offshore students. With a two letter grade reduction exchange rate, more than fifty percent would not have met the graduation requirements of the home university. ${ }^{8}$ Furthermore, Chinese course pass grade is not aligned with the business program policy. As mentioned above, the passing grade for the Canadian university's business courses is C-, while for the offshore programs, the passing percentage grade translates to a $\mathrm{C}$ letter grade. Translating the percentage grade received directly to a GP using policy ED (24) 3-2 would make the grading policy not comparable with the TRU grading system.

Until today, the re-alignment of the two grading systems was corrected by deducting 5 marks from the final percentage mark received from the offshore programs. ${ }^{9}$ Thus, a Chinese student who received a 60 in China would get a 55 in Canada - a 'just pass' grade in China, and this translates into a just pass grade in Canada. This reduction in grades is needed in order to align the two systems.

\section{ETHICAL AND FUNDAMENTAL ISSUES}

In post-secondary education, administrators and faculty are constantly making decisions with the goal of improving the educational system and enhancing student achievement. In order for them to make fair decisions that balance the best interests of the students with the needs of the institution it is important for researchers to provide faculty and administration with a valid analysis of research data as it pertains to the issues at hand. A Canadian institution working within the constraints of a Chinese educational system presents many challenges for both partners, one of which is the differences in grading systems as discussed in the introduction.

One of the problems with the ad hoc method of deducting 5 marks to scale the two systems into a uniform standard is an unfairness that arises in part of the grade distribution. ${ }^{10}$ When this deduction is made to all marks and they are then converted to a letter grade scale, many students in the mid-range may have their letter grade reduced by two GP steps, while the top and bottom letter grades will only be reduced by one GP step (Appendix B). This will significantly alter the grade point average calculations and, in turn, will lower the cumulative grade point average (CGPA) for offshore students, making it look lower than it should be. For example, a student receiving a percentage grade of 81 would move from an A- letter grade to a B letter grade. The GP in the course would fall from 3.67 to a value of 3, while a student that received a percentage grade of 65 would move from a $\mathrm{C}+$ letter grade to a $\mathrm{C}$ letter grade. The grade point drops only by 0.33 points, from 2.33 to a value of 2 . This problem will happen in a relatively common letter grade range of A-, B+ and B. Specifically, any percentage grade in the $77-81$ and in the 73 - 74 range will drop by two letter grades with the 5 mark deduction policy. Many students in the Chinese program obtain grades in this range, thus are treated unfairly relative to the other students.

A fairer system of scaling should be implemented before offshore graduating student averages are calculated from current CGPA's. A solution recommended in this paper is to convert the numerical grades received from the offshore programs to letter grades according to Table 1 and then lower these letter grades by one letter grade, except for students obtaining 95+ (Appendix "A").

\footnotetext{
${ }^{8}$ Most students perform in the good/satisfactory range given a normal bell shaped distribution of grades. The frequency of observing students in the minimum achievement and excellent range is smaller. Thus deducting two letter grades to align the systems will create a huge failure rate. This failure rate is not observed in post secondary institutions.

${ }^{9}$ In terms of logistics, the offshore program provides TRU the following information; student ID number, student name, gender, date of birth, semester, course names and acronyms, as well as the final percentage grade the student achieved in the courses. The faculty coordinator then deducts 5 marks from each percentage grade and then uses the above table to obtain the final letter grade. These letter grades are then submitted to the registrar for entry into the students' transcript. As an outcome the grade point system takes into effect to determine academic performance.

${ }^{10}$ Apart from the issue of fairness of deducting 5 marks.
} 
The data used in this study is obtained from Thompson Rivers University, a Canadian public degree granting post secondary institution offering an offshore BBA program in China with a current enrollment of approximately 800 students. The histogram in Figure 1 illustrates the CGPA of 135 graduates from the Tianjin program under the two grading systems. The new system (TUT_N) pulls the distribution to the right, increasing the average CGPA relative to the old CGPA (TUT_O). The average CGPA of the graduates increases from 2.75 to 2.84 with the change in the exchange rate. Notice the variance of the distribution remains unaffected by this change in policy.

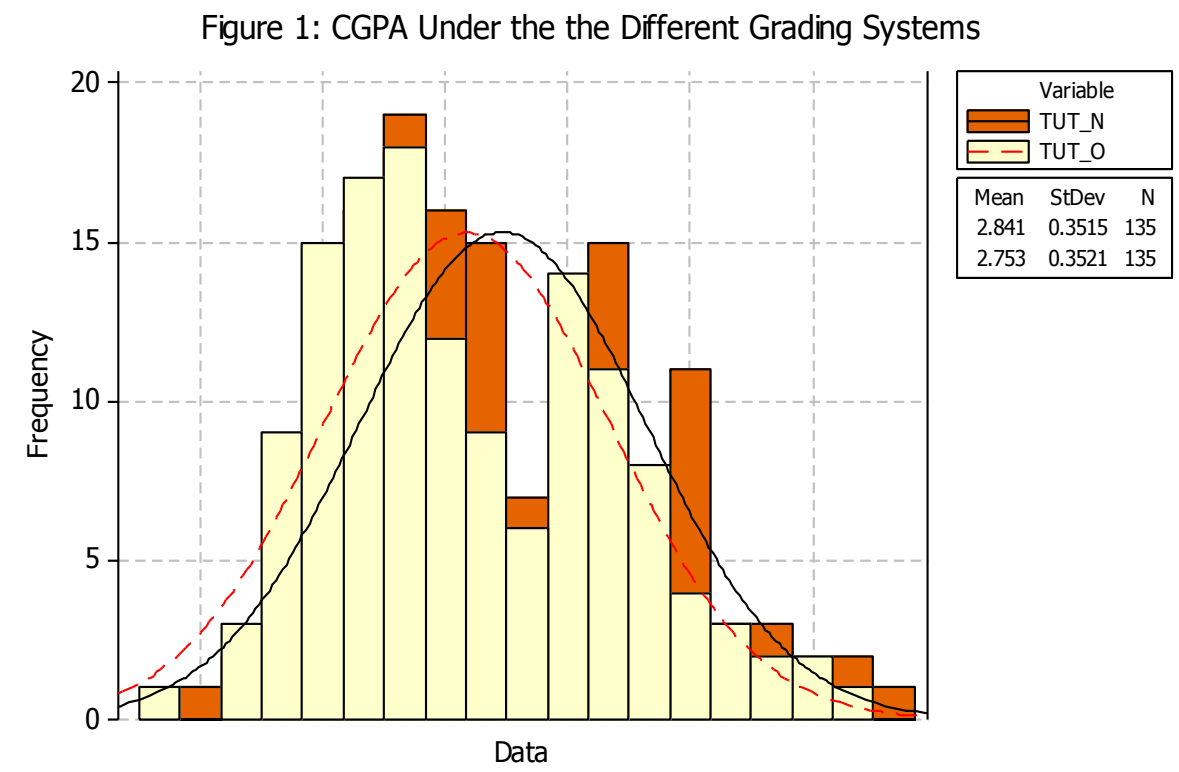

Table 3 provides additional information on the two grading systems. As expected, the average CGPA, median, minimum and maximum CGPA values increase. The standard error remains unchanged.

Table 3: CGPA Statistics from TUT Program

\begin{tabular}{|l|c|c|}
\hline \multicolumn{1}{|c|}{ CGPA Statistics } & $\begin{array}{c}\text { New Grading System: One Letter } \\
\text { Grade Deduction }\end{array}$ & $\begin{array}{c}\text { Old Grading System: 5 Mark } \\
\text { Deduction }\end{array}$ \\
\hline Average & 2.84 & 2.75 \\
\hline Standard Error & 0.03 & 0.03 \\
\hline Median & 2.78 & 2.68 \\
\hline Minimum & 2.08 & 2.01 \\
\hline Maximum & 3.76 & 3.74 \\
\hline
\end{tabular}

\section{COMPARISON WITH HOME UNIVERSITY}

If one were to ask a post secondary institution what is the cumulative grade point average (CGPA) of their typical business graduate? The answer would not be the top CGPA student of the program nor would the answer be the student with the lowest CGPA as these outcomes occur in the tail end of a normal-bell shaped distribution of CGPA values. As one would expect in a normal bell-shaped distribution, the average of the cumulative grade point average of the graduates would be a good indicator of a "typical" graduate. ${ }^{11}$ This graduate would probably have a

\footnotetext{
${ }^{11}$ The median would be another indicator if the distribution is not normal bell shaped.
} 
second class standing given that there are usually minimum CGPA requirements for graduation that are at the satisfactory level.

How does the home University cumulative grade point distribution compare with the distribution of transnational programs? This comparison is done for the purpose of developing a yardstick in which the fundamental value of the "exchange rate" between the two grading systems can be aligned. It also allows one to observe if population mean differences in CGPA between home and offshore students exists. Thus the hypotheses being tested are:

Null Hypothesis 1: The population mean value of the cumulative GPA of a home graduate is equal to a graduate from the transnational programs when the 5 mark deduction policy is instituted.

Null Hypothesis 2: The population mean value of the cumulative GPA of a home graduate equal to a graduate from the transnational programs when the letter grade is deduction policy is instituted.

Before testing for the validity of the above hypothesis, discussion will center on the distribution of grades of home graduates. The 2007 distribution of the cumulative grade point of 122 BBA graduating students from the Canadian University's program is presented and compared with the transnational programs.

A typical business graduate from the Canadian-based university in 2007 graduated with a cumulative grade point average of 2.88 , which is considered to be a very good standing (i.e., second class). The variability of cumulative grade point average of the TRU home student graduate is significantly larger than the student graduating from the TUT offshore program (See Figure 2). The standard deviation of the sample mean is .0474 . A $95 \%$ confidence interval for the population mean is in the range of $2.78-2.97$. The highest CGPA score was 4.09 and the lowest was a score of 2 .

\section{Figure 2: CGPA TRU Home and TUT Existing Grading Policy}

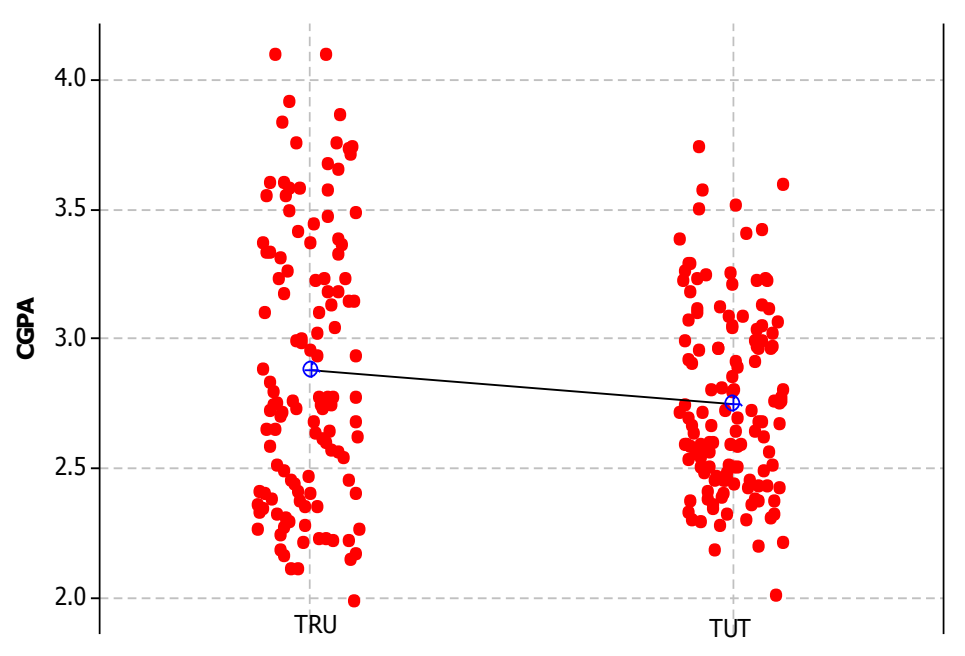

In comparison, the average cumulative GPA from the offshore programs are lower, but are they significantly lower to conclude that there are differences in population means? Table 4 below reports the t-test results for cross comparisons with the two transnational programs in China using the 5-mark deduction policy. It is clear that there is a statistically significant difference in the typical CGPA of a graduating student from the home university relative to the transnational program. The home university graduate performs better on average, but performance is dependent on the 5-mark deduction policy. When the average performances are compared using the letter grade deduction (Table 5), there is no statistical significant difference between the typical students in the offshore programs and the home university (p-values are reported in the parenthesis). 
Table 4: t-tests comparisons with 5 marks deducted

\begin{tabular}{|l|c|c|c|c|}
\hline & Graduates & Average & TUT-O & SIT-O \\
\hline TRU & 122 & 2.879 & $2.23(0.027)$ & $1.86(0.065)$ \\
\hline TUT-O & 135 & 2.753 & & $0.15(0.877)$ \\
\hline SIT-O & 68 & 2.761 & & \\
\hline
\end{tabular}

Note: SIT-0 is the SIT old transfer grading system.

Table 5: t-tests comparisons with one letter grade deducted

\begin{tabular}{|l|c|c|c|c|}
\hline & Graduates & Average & TUT-N & SIT-N \\
\hline TRU & 122 & 2.879 & $0.68(0.499)$ & $1.02(0.311)$ \\
\hline TUT-N & 135 & 2.841 & & $0.51(0.610)$ \\
\hline SIT-N & 68 & 2.814 & & \\
\hline
\end{tabular}

Note: SIT-N stands for SIT new grading transfer system

\section{CONCLUSION}

Transnational education is a global phenomenon that has caught the attention of academics around the world as educators try to grapple with ensuring academic success for their international students. The aim in this case study was to identify if the current practice of scaling student marks from the Chinese partner universities was appropriate and the hope is that this new knowledge will result in the ability of university administrators to make more informed policy decisions with regard to the calculation of cumulative grade point averages of students graduating from offshore programs.

As a result, the researchers recommend that there be an institutional policy change and that the Canadian university implement the letter grade reduction system for the re-alignment of Chinese student grades. The policy implications of this research are important for other universities or other departments at Thompson Rivers University who may be considering partaking in transnational programming and require data for the creation of institutional grading policies. The authors recognize the limitations of using a small sample size and intend to expand this research by collecting further data over a three-year period.

This case study was investigating a specific grading policy related to the administration of an off-campus Canadian BBA program with an international partner. Yet with the globalization of higher education, there are many research opportunities relating to the administration and quality control of offshore programs that should be investigated. While the knowledge obtained from this study will serve to enhance one small part of the administration of Thompson Rivers University's transnational programs, further research should examine quality assurance and relationships between gender, ethnicity, assessment methods, cultural differences and academic performance of international students, both at home and offshore.

\section{ACKNOWLEDGEMENTS}

The authors would like to acknowledge Ashok Mathur, Sandra Vermeulen, Murry Young, Shane Rollan, Marion Hannaford, Baihua Chadwick, George Gong and the participants at the Clute 2007 College Teaching and learning conference for their valuable feedback. Financial support from TRU World and the School of Business and Economics is greatly appreciated.

\section{AUTHOR INFORMATION}

Margaret Hohner is a masters of education student at Thompson Rivers University, Kamloops, BC, Canada. Her research interest is in accreditation, quality assurance and transnational programs. Her thesis is an empirical examination of student beliefs regarding quality in post-secondary institutions.

Panagiotis Tsigaris is an Associate Professor of Economics at Thompson Rivers University, Kamloops, BC, Canada. He teaches introductory economics, statistics, public finance, cost benefit analysis and environmental economics. His diverse research interests span environmental economics, taxation policy and issues, decisions under risk, and economics education. 


\section{REFERENCES}

1. Abel, C. (2002), “Academic Success and the International Student: Research and Recommendations." New Directions for Higher Education, (117), 13-20.

2. ADMIT Project Team (2002), "Higher Education Admissions and Student Mobility: the ADMIT research project." European Educational Research Journal, 1(1), 151-172.

3. Altbach, P. G., \& Knight, J. (2006), "The Internationalization of Higher Education: Motivations and Realities." The NEA 2006 Almanac of Higher Education. Washington, D.C.: National Education Association, 27-36.

4. Bernardo, A. B. (2002), "International Higher Education: Models, Conditions and Issues." PASCN Discussion Paper No. 2001-12, Philippine Institute for Development Studies, Philippines, 1-50.

5. Chapman, A., \& Pyvis, D. (2006), "Quality, identity and practice in offshore university programmes: issues in the internationalization of Australian higher education." Teaching in Higher Education, 11(2), 233-245.

6. De Vita, G. (2002), "Cultural Equivalence in the Assessment of Home and International Business Management Students: a UK exploratory study." Studies in Higher Education, 27(2), 221-231.

7. Feagles, S.M.(ed) (1999), A Guide to Educational Systems Around the World. NAFSA: Association of International Educators.

8. Gift, S., Leo-Rhynie, E., \& Moniquette, J. (2006), "Quality Assurance of Transnational Education in the English speaking Caribbean." Quality in Higher Education, 12(2), 125-133.

9. Gribble, K., \& Ziguras, C. (2003), "Learning to Teach Offshore: Pre-Departure training for lecturers in transnational programs." Higher Education Research \& Development, 22(2), 205-211.

10. Jones, G. (2001), "Bridging the Challenges of Transnational Education and Accreditation." Higher Education in Europe, 26(1), 107-116.

11. Jones, E. \& Jackson, J. (1990) "College Grades and Labour Market Rewards." The Journal of Human Resources, 25 (2), 253.

12. Jochems, W., Snippe, J., Smid, H.M., \& Verweij, A. (1996), "The academic progress of foreign students: Study achievement and study behaviour." Higher Education, 31(3), 325-340.

13. Karran, T. (2004), “Achieving Bologna Convergence: Is ECTS Failing to Make the Grade?” Higher Education in Europe, 29, (3), 411-421.

14. Karran, T. (2005), "The Bologna Process: Retrospect and Prospects" Higher Education in Europe, 30, (1), $5-22$.

15. McBurnie, G., \& Ziguras, C. (2001), "The regulation of transnational higher education in Southeast Asia: Case studies of Hong Kong, Malaysia and Australia." Higher Education, 42(1), 85-105.

16. Morrison, J., Merrick, B., Higgs, S., \& Le Métais, J. (2005), "Researching the performance of international students in the UK." Studies in Higher Education, 30(3), 327-337.

17. Postman, Neil (1992) Technopoly: The Surrender of Culture to Technology . New York City: Alfred A. Knopf, 13.

18. Thompson Rivers University (TRU) Grading Policy 2007 http://www.tru.ca/assets/policy/ed/ed03-5.pdf

19. Van Damme, D. (2001) "Quality issues in the internationalization of higher education." Higher Education, $41(4), 415-441$. 


\section{APPENDICES}

\section{APPENDIX A}

Table A1: TRU and Chinese Grade Comparison (Where 60 is a Pass)

\begin{tabular}{|c|c|c|c|c|c|c|c|}
\hline $\begin{array}{c}\text { TRU } \\
\text { Letter Grade }\end{array}$ & $\begin{array}{c}\text { Chinese } \\
\text { Letter } \\
\text { grade }\end{array}$ & $\begin{array}{c}\text { TRU } \\
\text { Numerical } \\
\text { Grade }\end{array}$ & $\begin{array}{c}\text { Chinese } \\
\text { Numerical } \\
\text { Grade }\end{array}$ & $\begin{array}{l}\text { TRU Assessment } \\
\text { Description }\end{array}$ & $\begin{array}{c}\text { Chinese Assessment } \\
\text { Description }\end{array}$ & $\begin{array}{l}\text { TRU GP from TRU } \\
\text { Letter Grade }\end{array}$ & $\begin{array}{c}\text { TRU GP from } \\
\text { Chinese Letter Grade }\end{array}$ \\
\hline $\mathrm{A}-, \mathrm{A}, \mathrm{A}+$ & $\mathrm{A}$ & $80-100$ & $90-100$ & Excellent & Excellent & $3.67,4.0,4.33$ & 4.0 \\
\hline $\mathrm{B}-, \mathrm{B}, \mathrm{B}+$ & $\mathrm{B}$ & $70-79$ & $80-89$ & Very Good & Good & $2.67,3.0,3.33$ & 3.0 \\
\hline $\mathrm{C}, \mathrm{C}+$ & $\mathrm{C}$ & $60-69$ & $70-79$ & Satisfactory & Average/Fair & $2.0,2.33$ & 2.0 \\
\hline $\mathrm{C}-$ & $\mathrm{F}$ & $55-59$ & $0-59$ & Pass & Unsatisfactory/Fail & 1.67 & 0.0 \\
\hline $\mathrm{D}$ & $\mathrm{F}$ & $50-54$ & $0-59$ & Minimal Pass & Unsatisfactory/Fail & 1.0 & 0.0 \\
\hline $\mathrm{F}$ & $\mathrm{F}$ & $0-49$ & $0-59$ & Unsatisfactory/Fail & Unsatisfactory/Fail & 0.0 & 0.0 \\
\hline
\end{tabular}

\section{APPENDIX B}

Table A2: Current Offshore Grading System: 60+ is a pass

\begin{tabular}{|c|c|c|c|c|c|c|c|}
\hline $\begin{array}{l}\text { Numerical Grade } \\
\text { submitted to TRU from } \\
\text { Offshore Program }\end{array}$ & $\begin{array}{c}\text { Letter Grade without } \\
\text { adjustment }\end{array}$ & $\begin{array}{c}\text { Grade Point } \\
\text { without } \\
\text { adjustment }\end{array}$ & $\begin{array}{c}\text { TRU Grade } \\
\text { Range after } \\
\text { deducting } 5 \\
\text { marks }\end{array}$ & $\begin{array}{c}\text { Letter Grade } \\
\text { granted at TRU }\end{array}$ & $\begin{array}{l}\text { Grade Point } \\
\text { recorded at } \\
\text { TRU }\end{array}$ & \multicolumn{2}{|c|}{ Comments } \\
\hline $95-100$ & $\mathrm{~A}+$ & 4.33 & $90-95$ & $\mathrm{~A}+$ & 4.33 & \multicolumn{2}{|c|}{ Same as TRU } \\
\hline $90-94$ & $\mathrm{~A}+$ & 4.33 & $85-89$ & $\mathrm{~A}$ & 4 & \multicolumn{2}{|c|}{ 1 GP lower } \\
\hline $85-89$ & $\mathrm{~A}$ & 4 & $80-84$ & A- & 3.67 & \multicolumn{2}{|c|}{1 GP lower } \\
\hline 80-84 & A- & 3.67 & $75-79$ & $\mathbf{B}$ or $\mathbf{B}+$ & 3 or 3.33 & $\begin{array}{l}1 \text { or } 2 \text { GP } \\
\text { lower }\end{array}$ & \multirow{3}{*}{$\begin{array}{l}\text { Area of concern } \\
\text { with current } \\
\text { system of } \\
\text { deducting } 5 \text { marks } \\
\text { in terms of fairness }\end{array}$} \\
\hline 77-79 & $\mathbf{B}+$ & 3.33 & $72-74$ & B- or B & 2.67 or 3 & $\begin{array}{l}1 \text { or } 2 \text { GP } \\
\text { lower }\end{array}$ & \\
\hline $73-76$ & B & 3 & $68-71$ & $\mathrm{C}+$ or B- & 2.33 or 2.67 & $\begin{array}{l}1 \text { or } 2 \text { GP } \\
\text { lower }\end{array}$ & \\
\hline $70-72$ & B- & 2.67 & $65-67$ & $\mathrm{C}+$ & 2.33 & \multicolumn{2}{|c|}{1 GP lower } \\
\hline $65-69$ & $\mathrm{C}+$ & 2.33 & $60-64$ & $\mathrm{C}$ & 2 & \multicolumn{2}{|c|}{1 GP lower } \\
\hline $60-64$ & $\mathrm{C}$ & 2 & $55-59$ & $\mathrm{C}-$ & 1.67 & \multicolumn{2}{|c|}{1 GP lower } \\
\hline $55-59$ & C- & 1.67 & $50-54$ & $\mathrm{D}$ & 1 & \multicolumn{2}{|c|}{1 GP lower } \\
\hline $50-54$ & $\mathrm{D}$ & 1 & less than 50 & $\mathrm{~F}$ & 0 & \multicolumn{2}{|c|}{1 GP lower } \\
\hline $0-49$ & $\mathrm{~F}$ & 0 & & & & & \\
\hline
\end{tabular}


NOTES 